\title{
MENINGKATKAN KEMAMPUAN SOSIAL EMOSIONAL ANAK USIA 3-4 TAHUN MELALUI KEGIATAN MORNING FUN DI KB KHADIJAH PANDEGILING SURABAYA
}

\author{
Jauharotur Rihlah $^{1}$, Andini Hardiningrum ${ }^{2}$ \\ Universitas Nahdlatul Ulama Surabaya \\ ${ }^{1}$ rihlahjauhara@unusa.ac.id \\ ²andinihardiningrum@unusa.ac.id
}

\begin{abstract}
Abstrak : Morning fun merupakan salah satu strategi pembelajaran yang diterapkan kepada anakanak pada pagi hari sebagai kegiatan peralihan dari rumah ke sekolah dengan konsep bermain menyenangkan dan sesuai minat anak. Kegiatan morning fun sangatlah penting bagi anak, karena saat pagi hari anak-anak membutuhkan suasana yang menyenangkan sehingga dapat mempengaruhi proses belajar anak di sekolah dan aspek perkembangan anak. Morning fun bertujuan merangsang anak untuk bermain bersama dengan teman, bermain mandiri, bergerak bebas, melatih motorik halus anak. Morning Fun merupakan aplikasi antara kegiatan junal pagi dengan model pembelajaran independent learning. Jurnal pagi merupakan proses transisi bagi anak dari rumah ke sekolah. Tujuan penelitian ini adalah untuk mengetahui peningkatan kemampuan sosial emosional melalui kegiatan morning fun di KB Khadijah Pandegiling Surabaya. Desain Penelitian yang digunakan adalah Penelitian Tindakan Kelas (PTK). Subjek penelitian ini yaitu anak usia 3-4 tahun di KB Khadijah Pandegiling Surabaya. Hasil penelitian menunjukkan nilai rata-rata kemampuan sosial emosional sebelum penerapan kegiatan morning fun (prasiklus) 54,25\% dan nilai rata-rata kemampuan sosial emosional sesudah penerapan kegiatan morning fun (siklus II) $86,25 \%$, sehingga memperoleh peningkaan kemampuan sosial emosional melalui kegiatan morning fun sebanyak 32\%. Simpulan dari penelitian ini adalah ada peningkaan kemampuan sosial emosional melalui kegiatan morning fun di KB Khadijah Pandegiling Surabaya.
\end{abstract}

\section{Kata Kunci: Kemampuan sosial emosional, Kegiatan Morning Fun}

Abstract : Morning fun is wrong one learning strategy that is applied to children in the morning as a transition activity from home to school with the concept of playing fun and according to the interests of the child.activities are Morning fun very important for children, because during the morning children need a pleasant atmosphere so that they can influence the learning process of children in school and aspects of child development. Morning fun aims to stimulate children to play together with friends, play independently, move freely, train children's fine motor skills. Morning Fun is an application between morning activities with anmodel independent learning. Morning journal is a transition process for children from home to school. The purpose of this study was to determine the improvement of social emotional abilities throughactivities morning fun at KB Khadijah Pandegiling Surabaya. The research design used was Classroom Action Research (CAR). The subjects of this study were children aged 3-4 years at KB Khadijah Pandegiling Surabaya. The results showed the average value of social emotional abilities before the application of morning fun (prasiklus) activities $54.25 \%$ and the average value of social emotional abilities after the application of morning fun activities (cycle II) $86.25 \%$, thus obtaining an increase in social emotional abilities through morning fun activities as much as $32 \%$. The conclusion of this study is that there is an increase in social emotional abilities through morning fun activities at KB Khadijah Pandegiling Surabaya.

\section{Keywords: Social emotional ability,Activity Morning Fun}




\section{PENDAHULUAN}

Pendidikan anak usia dini adalah suatu upaya pembinaan yang ditujukan kepada anak sejak lahir sampai dengan usia enam tahun yang dilakukan melalui pemberian rangsangan pendidikan untuk membantu pertumbuhan dan perkembangan jasmani dan rohani agar anak memiliki kesiapan dalam memasuki pendidikan lebih lanjut (UU No. 20 Th. 2003 tentang sisdiknas). Pendidikan anak usia dini merupakan landasan terpenting bagi perkembangan anak.

Seldin (dalam Yuliani : 2004.2) menyatakan bahwa pada rentang usia lahir sampai enam tahun anak mengalami masa keemasan (the golden age) yang merupakan masa dimana anak mulai peka/sensitif untuk menerima berbagai rangsangan. Masa peka pada masingmasing anak berbeda, seiring dengan laju pertumbuhan dan perkembangan anak secara individual. Masa ini juga merupakan masa peletak dasar pertama untuk mengembangkan kemampuan kognitif, bahasa, gerak-motorik, dan sosioemosional pada anak usia dini.

Banyak sedikitnya stimulasi yang diterima oleh seorang anak akan berdampak pada perkembangan selanjutnya. Aspek perkembangan yang harus di berikan kepada anak sejak dini salah satunya yaitu perkembangan sosial emosional.

Perkembangan sosial emosional anak dapat berupa taat pada aturan, sabar menunggu giliran, tanggung jawab, dan mandiri. Perkembangan sosial emosional merupakan salah satu aspek dari perkembangan Anak Usia Dini. Perkembangan sosial emosional anak dimulai dari egosentris individual yang artinya hanya memandang dari satu sisi yaitu dirinya sendiri, konsep diri dan kontrol diri kemudian secara bertahap menuju kearah berinteraksi dengan orang lain (Direktorat PAUD, 2003).

Syamsudin (1995: 105) mengungkapkan bahwa sosialisaasi adalah proses belajar untuk menjadi makhluk soaial. Adapaun Hurlock (1978: 250) bahwa perkembangan sosial merupakan perolehan kemampuan berperilaku yang sesuai dengan tuntutan sosial. Goleman (1995: 411) menyatakan bahwa emosi merujuk pada suatu perasaan atau pikiran-pikiran khasnya, suatu keadaan biologis dan psikologis serta serangkaian kecenderungan untuk bertindak. Syamsudin (1990: 69) mengemukakan bahwa emosi merupakan suatu suasana yang kompleks (a complex feeling state) dan getaran jiwa (stid up state) yang menyertai atau muncul sebelum atau sesudah terjadinay suatu perilaku. Emosi merupakan suatu keadaan yang kompleks, dapat berupa perasaan ataupun getaran jiwa yang ditandai oleh perubahan 
biologis yang muncul menyertai terjadinya suatu perilaku. Perkembangan sosial emosional sangatlah penting karena semakin banyaknya permasalahan yang terjadi di sekitar anak, misalnya lingkungan yang tidak baik akan membawa dampak yang luar biasa pada anak. Anak memiliki masa emas perkembangan sosial emosional sesuai dengan tahap perkembangannya. Sehingga kebutuhan anak harus dilengkapi seoptimal mungkin agar tidak ada satu tahapan yang terlewatkan.

Idealnya perkembangan sosial emosional anak terlihat ketika anak mampu memilih teman bermain, memulai interaksi sosial dengan anak lain, berbagi makanan, memint izin untuk memakai benda orang lain, mengekspresikan sejumlah emosi melalui tindakan, katakata ekspresi wajah, menunda keinginan, menikmati kedekatan sementara dengan salah satu teman, menunjukkan kebanggaan terhadap keberhasilannya, dan dapat memecahkan masalah dengan teman sekelas melalui proses pergantian, persuasi dan negosiasi.

Kenyataan di lapangan perkembangan sosial emosional dan fisik motorik anak usia 34 tahun (kelompok bermain) di KB Khadijah Pandegiling Surabaya masih belum berkembang dengan baik. Dalam aspek perkembangan sosial emsoional, $80 \%$ anak masih belum bisa berpisah dengan orang tuanya, bahkan masih banyak yang masih menangis saat ditinggal oleh orang tuanya, belum bertanggung jawab (beres-beres), belum bisa bersabar ketika bermain. Ketika bermain anak-anak masih terlihat masih membutuhkan bantuan dari orang lain.

Berdasarkan kenyataan di lapangan, maka pemberian strategi pembelajaran untuk mengembangkan sosial emosional dan fisik motorik anak di KB Khadijah Pandegiling Surabaya sangatlah penting. Salah satu cara untuk mengembangkan kemampuan sosial emosional anak dalam hal kemandirian, sabar dan tanggung jawab yaitu dengan melalui kegiatan Morning Fun.

Morning fun merupakan salah satu strategi pembelajaran yang diterapkan kepada anak-anak pada pagi hari sebagai kegiatan peralihan dari rumah ke sekolah dengan konsep bermain menyenangkan dan sesuai minat anak. Kegiatan morning fun sangatlah penting bagi anak, karena saat pagi hari anak-anak membutuhkan suasana yang menyenangkan sehingga dapat mempengaruhi proses belajar anak di sekolah dan aspek perkembangan anak. Morning fun bertujuan merangsang anak untuk bermain bersama dengan teman, bermain mandiri, bergerak bebas, melatih motorik halus anak. 
Berdasarkan hal-hal tersebut diatas, mengunggah keinginan peneliti untuk melakukan penelitian tentang Morning Fun untuk Menstimulasi Perkembangan Sosial Emosional dalam hal kemandirian, sabar, dan bertanggung jawab pada Anak Usia (3-4) Tahun di KB Khadijah Pandegiling Surabaya.

Peran"

\section{METODE}

Penelitian ini menggunakan observasional Penelitian Tindakan Kelas (PTK). Menurut Arikunto (2015:2) Penelitian Tindakan Kelas atau PTK adalah jenis penelitian yang memamparkan baik proses maupun hasil, yang melakukan PTK di kelasnya untuk meningkatkan kualitas pembelajarannya. Penelitian Tindakan Kelas (PTK) atau Class room Action Research (CAR) secara sederhana dapat diartikan sebagai penelitian yang dilakukan di kelas (Wardoyo, 2013:2).

Menurut McNiff (dalam Kanca, 2010:108), memandang "PTK sebagai bentuk penelitian refektif yang dilakukan oleh guru sendiri yang hasilnya dapat dimanfaatkan sebagai alat untuk pengembangan kurikulum, pengembangan sekolah, dan pengembangan keahlian mengajar". Dari beberapa pendapat diatas, maka dapat disimpulkan, pengertian penelitian tindakan kelas (PTK) adalah penelitian yang dilakukan dengan berbagai tindakan tertentu yang bertujuan untuk memperbaiki dan meningkatkan praktik pembelajaran di kelas.

Dalam penelitian tindakan ini menggunakan bentuk pendidik sebagai peneliti, penanggung jawab penuh penelitian ini adalah pendidik. Tujuan utama dari penelitian tindakan ini adalah untuk meningkatkan kemampuan sosial emosional anak melalui metode bermain peran, dimana pendidik secara penuh terlibat dalam penelitian mulai dari perencanaan, tindakan, pengamatan dan refleksi. Dalam penelitian ini peneliti tidak bekerjasama dengan siapapun, kehadiran peneliti sebagai pendidik dan sebagai pengajar tetap melaksakan kegiatan belajar mengajar seperti biasa, sehingga peserta didik tidak tahu kalau sedang diteliti.

\section{HASIL DAN PEMBAHASAN}

1. Hasil prasiklus

Peneliti melakukan pengamatan sebelum melakukan penelitian tindakan kelas bertujuan untuk mengetahui kondisi awal (pra siklus) anak sebelum melakukan tindakan. 
Peneliti akan melakukan penelitian tentang peningkatan kemampuan sosial emosional melalui kegiatan moning fun, subjek penelitian ialah anak usia 3-4 tahun berjumlah 20 anak. Kegiatan pengamatan dilaksanakan pada inti. Berikut adalah tabel peningkatan kemampuan sosial emosional melalui kegiatan moning fun (Prasiklus):

Tabel 4.1 Hasil peningkatan kemampuan sosial emosional melalui kegiatan moning fun (Prasiklus)

\begin{tabular}{|l|l|l|l|}
\hline Skor & Capaian Kemampuan sosial emosional & Jumlah Anak & Presentase \\
\hline 4 & Baik (B) & 8 & $40 \%$ \\
\hline 3 & Cukup (C) & - & - \\
\hline 2 & Sedang (S) & 9 & $45 \%$ \\
\hline 1 & Kurang (K) & 3 & $15 \%$ \\
\hline Jumlah & & 20 & $100 \%$ \\
\hline
\end{tabular}

Berdasarkan anak tabel 4.1 dari 20 anak didapatkan bahwa 8 anak (40\%) kemampuan sosial emosional pada prasiklus baik, 9 anak (45\%) kemampuan sosial emosional pada prasiklus sedang, 3 anak (15\%) kemampuan sosial emosional pada prasiklus kurang.

2. Hasil siklus I dan siklus II

a. Hasil siklus I

Pengamatan dilakukan untuk mengetahui peningkatan kemampuan sosial emosional melalui kegiatan moning fun. Siklus I terdapat dua pertemuan, pertemuan pertama dilaksanakan pada tanggal 3 Januari 2019 sedangkan pertemuan ke dua dilaksanakan pada tanggal 4 januari 2019. Berikut adalah tabel hasil peningkatan kemampuan sosial emosioanl setiap anak melalui kegiatan bermain peran (Siklus I pertemuan 1 dan 2):

Tabel 4.2 Hasil Kemampuan sosial emsoioanl anak melalui kegiatan morning fun (Siklus I Pertemuan 1)

\begin{tabular}{|l|l|l|l|}
\hline Skor & Capaian Kemampuan sosial emosional & Jumlah Anak & Presentase \\
\hline 4 & Baik (B) & 5 & $25 \%$ \\
\hline 3 & Cukup (C) & 7 & $35 \%$ \\
\hline 2 & Sedang (S) & 8 & $40 \%$ \\
\hline 1 & Kurang (K) & - & - \\
\hline Jumlah & 20 & $100 \%$ \\
\hline
\end{tabular}


Berdasarkan tabel 4.2 dari 20 anak pada siklus I pertemuan 1 didapat sebagian besar 8 anak (40\%) kemampuan sosial emosional anak sedang, dan sebagian kecil 5 anak (25\%) kemampuan sosial emosional anak baik.

Tabel 4.3 Hasil Kemampuan sosial emosional anak melalui kegiatan morning fun (Siklus I Pertemuan 2)

\begin{tabular}{|l|l|l|l|}
\hline Skor & Capaian Kemampuan sosial emosional & Jumlah Anak & Presentase \\
\hline 4 & Baik (B) & 8 & $40 \%$ \\
\hline 3 & Cukup (C) & 11 & $55 \%$ \\
\hline 2 & Sedang (S) & 1 & $5 \%$ \\
\hline 1 & Kurang (K) & - & - \\
\hline Jumlah & 20 & $100 \%$ \\
\hline
\end{tabular}

Berdasarkan tabel 4.3 dari 20 anak pada siklus I pertemuan 2 didapat sebagian besar 11 anak (55\%) kemampuan sosial emosional anak cukup, dan sebagian kecil 1 anak (5\%) kemampuan sosial emosional anak sedang.

b. Hasil siklus II

Pengamatan dilakukan untuk mengetahui peningkatan kemampuan sosial emosional melalui metode bermain peran pada anak usia 3-4 tahun di PPT Rindang. Siklus II terdapat dua pertemuan, pertemuan pertama dilaksanakan pada tanggal 7 Januari 2019 sedangkan pertemuan ke dua dilaksanakan pada tanggal 8 Januari 2019. Berikut adalah tabel hasil peningkatan kemampuan sosial emosional setiap melalui kegiatan morning fun (Siklus II pertemuan 1 dan 2):

Tabel 4.4 Hasil Kemampuan sosial emosional anak melalui kegiatan morning fun (Siklus II Pertemuan 1)

\begin{tabular}{|l|l|l|l|}
\hline Skor & Capaian Kemampuan sosial emosional & Jumlah Anak & Presentase \\
\hline 4 & Baik (B) & 13 & $65 \%$ \\
\hline 3 & Cukup (C) & 7 & $35 \%$ \\
\hline 2 & Sedang (S) & - & - \\
\hline 1 & Kurang (K) & - & - \\
\hline Jumlah & 20 & $100 \%$ \\
\hline
\end{tabular}


Berdasarkan tabel 4.4 dari 20 anak pada siklus II pertemuan 1 didapat sebagian besar 13 anak (65\%) kemampuan sosial emosional anak baik, dan sebagian kecil 7 anak (35\%) kemampuan sosial emosional anak cukup.

Tabel 4.5 Hasil Kemampuan Kemampuan sosial emosional Anak melalui kegiatan morning fun (Siklus II Pertemuan 2)

\begin{tabular}{|l|l|l|c|}
\hline Skor & Capaian Kemampuan sosial emosional & Jumlah Anak & Presentase \\
\hline 4 & Baik (B) & 20 & $100 \%$ \\
\hline 3 & Cukup (C) & - & - \\
\hline 2 & Sedang (S) & - & - \\
\hline 1 & Kurang (K) & - & - \\
\hline \multicolumn{2}{|l|}{ Jumlah } & 20 & $100 \%$ \\
\hline
\end{tabular}

Berdasarkan tabel 4.5 dari 20 anak pada siklus II pertemuan 2 didapat sebagian besar 20 anak $(100 \%)$ kemampuan sosial emosional anak baik.

c. Rekapitulasi hasil prasiklus, siklus I, siklus II

Berdasarkan hasil dari prasiklus, siklus I dan siklus II didapatkan peningkatan kemampuan sosial emosional anak melalui kegiatan morning fun di KB Khadijah Pandegiling Surabaya, lebih jelasnya berikut tabel rekapitulasi hasil prasiklus, siklus I dan siklus II:

Tabel 4.6 Hasil Rekapitulasi Peningkatan Kemampuan sosial emosional Anak melalui kegiatan morning fun(prasiklus, siklus I dan siklus II)

\begin{tabular}{|c|c|c|c|c|c|c|c|}
\hline \multirow[b]{2}{*}{ Skor } & \multirow{2}{*}{$\begin{array}{l}\text { Capaian Kemampuan sosial } \\
\text { emosional }\end{array}$} & \multicolumn{2}{|c|}{ Prasiklus } & \multicolumn{2}{|c|}{ Siklus I } & \multicolumn{2}{|c|}{ Siklus II } \\
\hline & & $\sum$ Anak & $\%$ & $\begin{array}{l}\sum_{\text {Anak }} \\
\text {. }\end{array}$ & $\%$ & $\sum$ Anak & $\%$ \\
\hline 4 & Baik (B) & 8 & 40 & 6 & 30 & 20 & 100 \\
\hline 3 & Cukup (C) & - & - & 13 & 65 & - & - \\
\hline 2 & Sedang $(\mathrm{S})$ & 9 & 45 & 1 & 5 & - & - \\
\hline 1 & Kurang (K) & 3 & 15 & - & - & - & - \\
\hline \multicolumn{2}{|c|}{ Jumlah } & 20 & 100 & 20 & 100 & 20 & 100 \\
\hline
\end{tabular}


Keterangan: $\sum=$ Jumlah

$\%=$ Presentase

Berdasarkan tabel 4.6 dari 20 anak memperoleh peningkatan dari sebelum tindakan (prasiklus) kemampuan sosial emosional anak semula sebagian besar sedang dan setelah melakukan tindakan pada tiap siklus memperoleh peningkatan pada siklus I kemampuan sosial emosional anak semula sebagian besar cukup dikarenakan pada indikator tanggung jawab anak hanya dapat menunjukkan kepedulian terhadap teman, mengikuti aturan dan arahan, menunggu giliran dalam suatu akivivtas sedangkan pada siklus II capaian kemampuan sosial emosional anak meningkat baik.

Sarannya Diharapkan dari adanya kegiatan morning fun dapat meningkatkan kemampuan sosial anak dalam segala hal. Pelatihan bagi guru-guru juga sangat penting dilakukan agar dapat menjadi contoh yang baik bagi anak didiknya

\section{REFERENSI}

Arikunto Suharsimi, Suhardjono dan Supardi. 2008. Penelitian Tindakan Kelas. Jakarta: Bumi Aksa.

Arikunto Suharsimi, Suhardjono dan Supardi. 2015. Penelitian Tindakan Kelas. Jakarta: PT Bumi Aksa.

Dimyati, Johni. 2013. Metodologi Penelitian dan Aplikasinya pada Pendidikan Anak Usia Dini (PAUD). Jakarta: KENCANA PRENADA MEDIA GROUP.

Djamarah, Syaiful Bahri dan Aswan Zain. 2010. Strategi Belajar Mengajar. Jakarta: Rineka Cipta.

Geldard, K dan Geldard, D. 2010. Konseling Anak-anak. Jakarta: PT.Indeks.

Gunarti Winda, Lilis Suryani, Azizah Muis. 2008. Metode Pengembangan dan Kemampuan Dasar Anak Usia Dini. Jakarta: UT.

Hurlock, E., B. 1978. Perkembangan Anak, Jilid 1. Jakarta: Erlangga.

Hurlock, E., B. 1980. Psikologi Perkembangan Suatu Pendekatan Sepanjang Rentang Kehidupan, Jilid 5. Jakarta: Erlangga. 